\title{
correspondence
}

\section{Researchers Information Exchange}

SIR, - Neither your editorial Time for a policy on scientists' jobs (1 November, page 1) nor the report by Joe Schwartz on Portrait of the out-of-work scientist (1 November, page 7) deserve to pass unnoticed. It is high time that the maximum of serious attention was given to the undoubted crisis which has developed in medical research and in research in other fields. The case of Dr Ann Simmonds and the Purine Laboratory at Guy's Hospital is only the tip of an uncompromising iceberg, that in the not too distant future is certain to confirm at last the United Kingdom's position as a third rate economic and scientific power, with a complement of first rate scientists, and scientific opportunities going to waste. Now is the time to ask "How long is it?" until that future comes to pass.

Some months ago the Association of Researchers in Medical Science committee received a very stony answer from the Department of Education and Science when they entered a plea to the Secretary of State to initiate a major inquiry into the scientific research sector (in a time of constraint and crisis), with particular reference to the conditions of employment of scientists and support staffs. In the meantime researchers' organisations, trades unions and campus opinion has been mobilised to publicise the plight of many researchers and scientists (in all disciplines).

The need to act in order to protect and develop conditions of work now seems a necessary distraction that research workers must pursue for their own survival and for our scientific future.

Government complacency and indifference in these matters is no longer defensible. In fact, some gesture from that quarter might redeem the situation before it gets really out of hand.

May I, through your columns, appeal to researchers and scientists to press energetically for a major review of the whole research and development sector, by the combined efforts of government, scientific and professional agencies. If our current economic straits do not allow the full panoply of review, at least a start must be made to identify problems and solutions so that scientific research policy can once again be adequate and informed. If action is not initiated soon we must accept irretrievable losses and delays to scientific progress, and technological and social applications. Can we bear to estimate our regret in five or ten years time by not having taken a positive stance now?

In the immediate future researchers and scientists must take steps to collaborate and coordinate their efforts in what is likely to become a bitter political battle if no firm action to seek just remedies is taken.

To this end a group of researchers (including myself and Dr Simmonds) have already established and gathered support for a Researchers Information Exchange to collect, analyse and distribute information on all aspects of research and development, relating to employment and conditions of work, and in the broader area of organisation, cooperation, funding, planning and policy-making. A recent meeting of RIE participants at Leicester University voiced the need for unified policies in the field of research, and it is to this end that readers and colleagues are urged to lend their support to this venture as a first stage in self-help to ensure the continued existence of a viable scientific community in this country. Yours faithfully, STEPHEN ROBERTS Loughborough University, Leicestershire, UK.

\section{Life-time of research for minority only}

SIR, - You are right to say (1 November, page 1) that hard thinking is needed about the nature of scientific careers. As I have argued elsewhere, however (New Scientist, 17 May 1973) one of the foundations for such thinking must be that research alone cannot provide a life-time career for any but a minority. Until this unpleasant truth is more widely

recognised, we shall continue to have the waste and personal tragedy which you illustrate in the same issue as your leader. Yours faithfully,

London W4, UK.

D.W. BUDWORTH

\section{Alexander Lerner: a call for action}

SIR, - We are extremely disturbed about the case of the distinguished Soviet scientist, Professor Alexander Lerner, who for eight years has been incurring the displeasure of the Soviet authorities because he applied for permission to emigrate to Israel. Professor Lerner was Director of the Department of Large Scale Systems at the Institute of Control Sciences, and among his publications is a well known text book, Fundamentals of Cybernetics, which has appeared in many languages.

Following his application for a visa he was: dismissed from his post and the Communist Party and forbidden to teach any students; expelled from the Editorial Board of the journal Automation and Telemechanics; removed from the public office of Chairman of the Scientific and Technical Committee of the University of Moscow. An attempt was also made to remove him from the post of local deputy Chairmanship of the Committee of the International Federation on Automation Administration which was rejected by the Federation.

After selling 40,000 copies, his book The Beginning of Cybernetics was taken out of production and his contract for this publication cancelled because of "mistakes in the manuscript", although a translation was published in many countries and it was recommended for the Competition of Best Books in 1967. The book Optimal Heating of Metals of which he was the scientific editor and one of the authors, was published in 1972 by the Metallurgy publishing house without his name being mentioned and without any reference to his works which are of fundamental value in this sphere. He has been prevented from attending conferences both within his own country and abroad.

Professor Lerner's daughter received a mathematics degree at the age of 15 . In 1974 she and her husband were allowed to emigrate to Israel where they now live with their two children. Professor Lerner who is 66 years old has never seen his youngest grandchild.

We are endeavouring to ameliorate the fate of this man who is isolated from his scientific colleagues and his work. His many interests clearly lie within those fields covered by the International Federation of Automatic Control (IF AC). We hope that these international scientific bodies such as IFAC wil show they have a clear duty to defend the rights of scientists working in their subject area. We therefore publicly call upon the IFAC Executive Council and National Member (Organisations to consider seriously the fulfilrnent of their obligations in the case of Professor Lerner.

$$
\text { Yours faithfully, }
$$

Peter ARCHER for the parliamentary contingent

DAVIDSHEPPARD

Nevill MotT

for the scientific contingent

The L.erner Circle, London NW3, UK.

\section{European ingenuity in particle physics}

Sir, -We write to correct some of the more grossly misleading impressions generated by the careless journalism of your article entitled "Can Yankee ingenuity keep US physics on the ball?'" (1 November, page 2).

The reference to PEP as the machine "expected to be the first to discover the $Z^{\circ}$ " is obviously, from its context, a mistake for the antiproton-proton ( $\overline{\mathrm{p} p}$ ) collider now under construction at CERN. This machine is made possible by European ingenuity displayed in the development of beam 'cooling' techniques - stochastic cooling was invented at CERN and electron cooling at Novosibirsk in the USSR. The feasibility of cooling $\bar{p}$ beams has been demonstrated at CERN and the $\bar{p} p$ collider project quickly launched to use the SPS ring as a store of both $\vec{p}$ and $\mathrm{p}$. The similar project at Fermilab which you mention is totally dependent upon these techniques.

The method proposed by Richter to achieve collisions of 40 to $50 \mathrm{GeV}$ electrons and positrons is indeed relatively cheap as it depends upon the existence of an expensive two mile long accelerator at SLAC, built in the late 1960s and the only one of its kind in the world. We applaud the ingenuity of this proposal and hope that the very formidable technical problems can be overcome.

However, even if successful, this device cannot attempt the fundamental research for which LEP is deliberately designed; that is, not only to make a complete study of $Z^{\circ}$ physics but to allow the most searching investigation of the weak, electromagnetic and strong interactions, performing vital tests of the gauge theory approach - such as the one due to Salam and Weinberg - which promises a unified understanding of these forces. These objectives require positron and electron energies approaching $100 \mathrm{GeV}$, not attainable at SLAC.

The last decade has baen a time of dramatic advance in our knowledge and understanding of fundamental physical processes and we welcome the enterprise and ingenuity being exercised by physicists and engineers, both in Europe and the US, to bring nearer the crucial tests so eagerly awaited. Yours faithfully 